\title{
HYDRAULIC PRESSURE FED SYSTEM USING HELIUM GAS AND FAST ELECTRO- HYDRAULIC ACTUATOR APPLIED TO BRAZILIAN SOUNDING ROCKETS AND MICROSATELLITE LAUNCHERS
}

\author{
Euler C. M. Gonçalves Barbosa \\ Aeronautics and Space Institute \\ (DCTA/IAE), São José dos Campos, \\ São Paulo, Brazil
}

\author{
Luiz C. S. Góes \\ Technological Institute of Aeronautics \\ (DCTA/ITA), São José dos Campos, \\ São Paulo, Brazil
}

\author{
Thiago Scharlau Xavier \\ Technological Institute of Aeronautics \\ (DCTA/ITA), São José dos Campos, \\ São Paulo, Brazil
}

\begin{abstract}
This work presents the research and technological development of a hydraulic high Pressure Fed System (named PFS) using Nitrogen/Helium gas and a fast electro-hydraulic actuator (FEHA) applied to movable nozzles for Brazilian sounding rockets and microsatellite launchers. The preliminary control capability analysis to sounding rockets design requires a high performance FEHA, e. g. the bandwidth, to perform the attitude control using the Thrust Vector Control (TVC) strategy. The Thrust Vector Assembly (TVA) consist of the PFS mounted on the EHA that controls the nozzle angular movement, in closed-loop operation. Modeling and simulation results using AMEsim environment show the PFS performance compared to step-unit response obtained from experimental tests. Frequency Response Functions (FRF) are obtained from experimental data using sinusoidal signals of excitation with frequency from 1 to $10 \mathrm{~Hz}$, and the bandwidth $B_{w}$ is accessed. Equipment to the PFS includes a pressure regulator to the helium gas in order to pressurize the hydraulic fluid with a constant pressure of $200 \mathrm{bar}$. A high performance electro-valve controls the oil flow in the hydraulic cylinder and a real-time digital controller is implemented to stabilize the closed loop. The results are of very interest if compared to the European actuator flight model of the Brazilian satellite launcher vehicle VLS-1. Details and improvements are discussed in order to obtain best bandwidth in the next FEHA engineering model, e.g. the digital flow control technique to the servo-valve.
\end{abstract}

Keywords: pressure system, electro-hydraulic actuator, control system

\section{INTRODUCTION}

The VLM-1 is a Microsatellite Vehicle Launcher being developed at the Brazilian Institute of Aeronautics and Space (DCTA/IAE) presented in the Figure 1 and discussed in Ettl [1]. It is designed to launch small satellites (Mini-, Micro- and Nano-Satellites) with mass less than $150 \mathrm{~kg}$, to equatorial and polar orbits. Its basic configuration consists of two stages with S50 propellant solid motors with about 10 tons of propellant and a S44 motor. The attitude of the vehicle during its flight is controlled by a Thrust Vector Assembly, shown in the Figure 1, maintaining the nominal attitude of reference, according to [2, 9]. The TVA system consists of a movable nozzle (angular displacement) controlled by a hydraulic actuator (linear displacement) in closed-loop operation (real time system) and must offer a minimum $3 \mathrm{~Hz}$ bandwidth for control capability requirements, discussed in $[6,7]$. The hydraulic energy to the actuator is provided by a Pressure Fed System, shown in the Figure 3, and actually is considered an engineering model (Figure 4). The basic equipment to the PFS are: accumulators filled with Nitrogen/Helium gas, pressure regulator, solenoid valve 2 ways/2 ports, gas/liquid cylinder to provide a 210 bar of pressure to the hydraulic actuator (Figure 2, right), pressure and temperature sensors. Dynamic and static tests are performed using the actuator work bench shown in the Figure 4, in which a well-known mass-spring is attached to the hydraulic actuator, the PFS is fixed to the servovalve and a closedloop is implemented for the actuator rod linear displacement. The hydraulic cylinder, named MAQDRAU, shown in the Figure 2 (right), was manufactured by Brazilian industries and assembled to a high dynamic servo-valve. Actually some improvements to the mechanical design are in course: mass optimization, compacted size, embedded LVDT linear sensor, stress and temperature analysis, steel/aluminum material definition, and digital control system. 

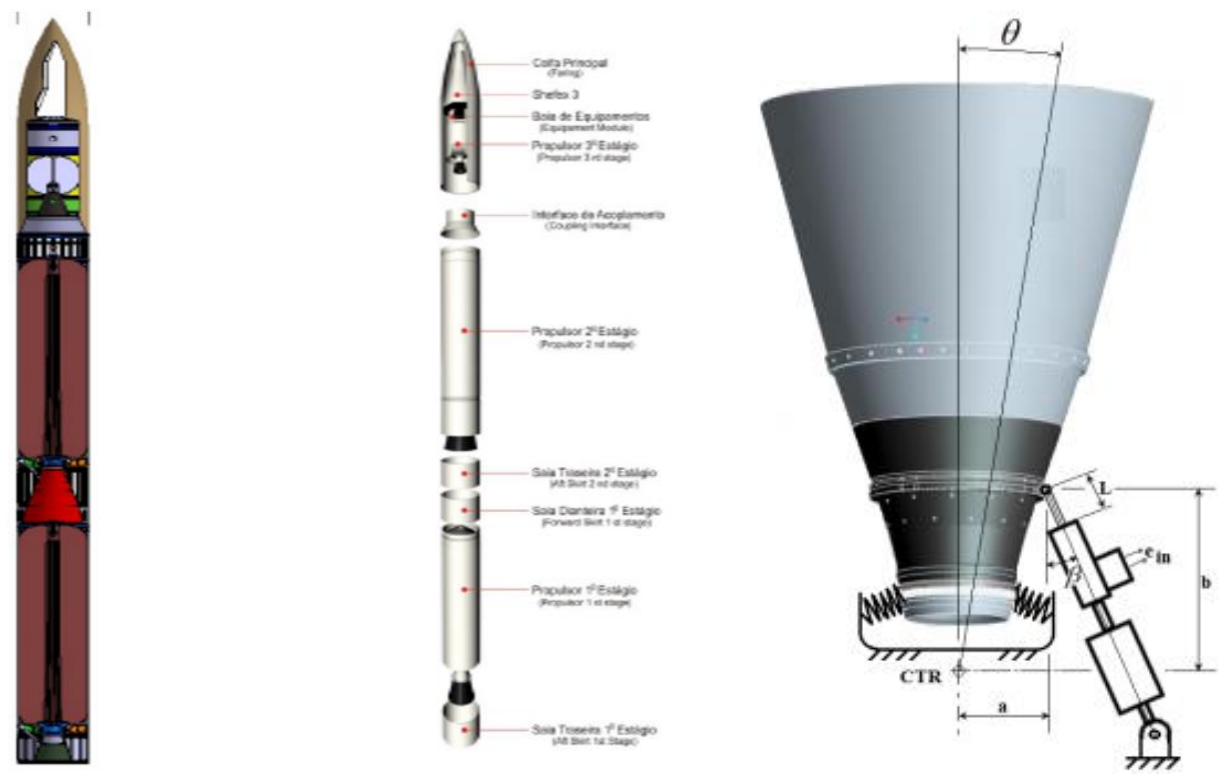

Figure 1, VLM-1 Basic configuration and the TVA system.
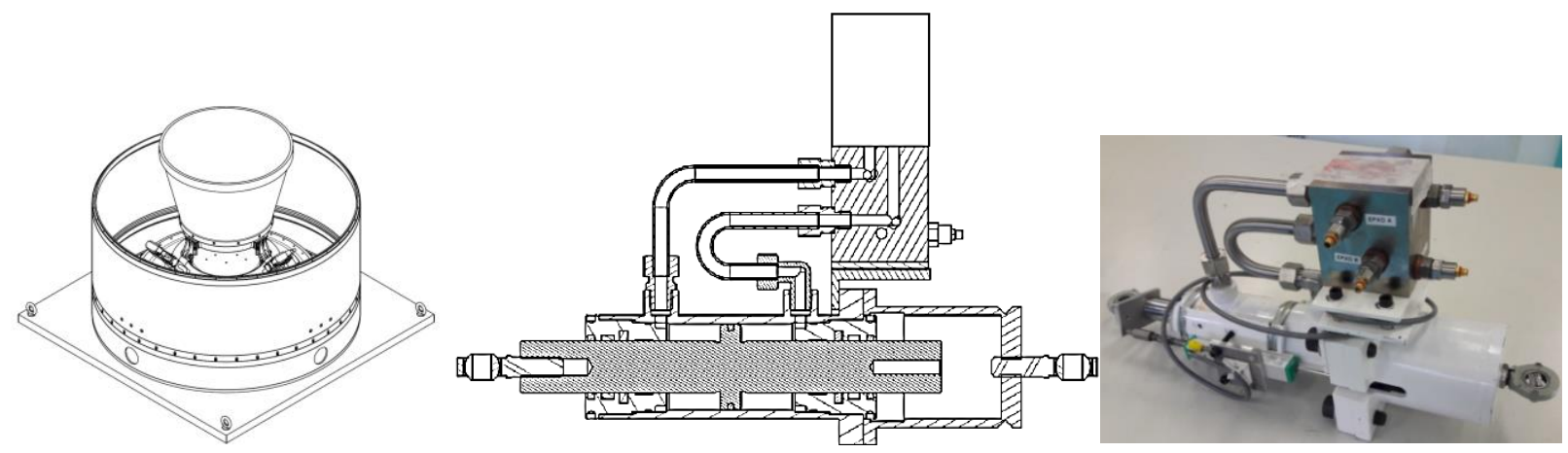

Figure 2: (left) TVA mechanical assembly, (center) MAQDRAU FEHA model and (right) MAQDRAU FEHA.

\section{PFS/FEHA MODELING AND SIMULATION}

The Figure 2 (right) presents the hydraulic actuator consisting of cylinder (steel), cube interface (steel), stainless steel pipes, an external linear LVDT sensor, two rod ends, 120/210 bar pressure performing $20 \mathrm{kN}$ of static force. The four pressure sensors are used for tests and system identification. A BOSCH servo-valve is mounted over the mechanical interface to control the fluid flow through the cylinder. The closed-loop operation is implemented using the LVDT sensor and a real-time digital controller (CompactRIO). AMEsim can produce mathematical models using state space equations (Equation (1)) as well as Bond-Graph technique to the complete system PFS/FEHA.

$$
\dot{x}=f(x, u)
$$

The PFS and the hydraulic actuator, shown in the Figure 4, can be modeled [3, 4] using the well-known BondGraph approach [5] or using the software AMESim from Siemens. The AMEsim is a mechatronics system simulation platform, from LMS International society, based on Bond-Graphs that models and simulates all system/subsystems of the PFS and hydraulic actuator. Thanks to a numerical solver, its Graphical User Interface allows modelling and analysis of multi-domain systems in different levels, depicted in Figure 5: functional and physical modelling, block-diagrams and programming. The block diagram of the TVA is depicted in Figure 3. 

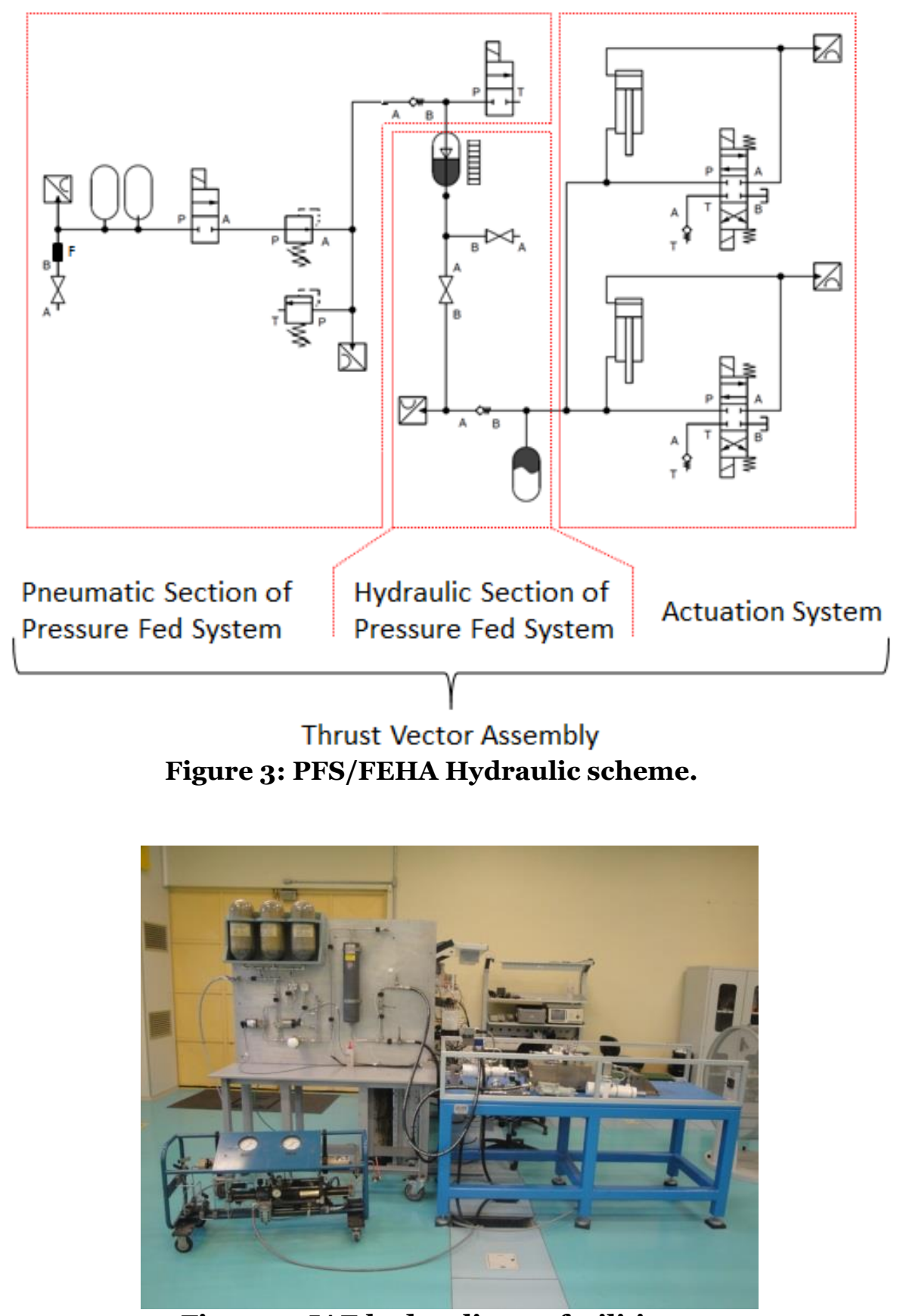

Figure 4: IAE hydraulic test facilities. 


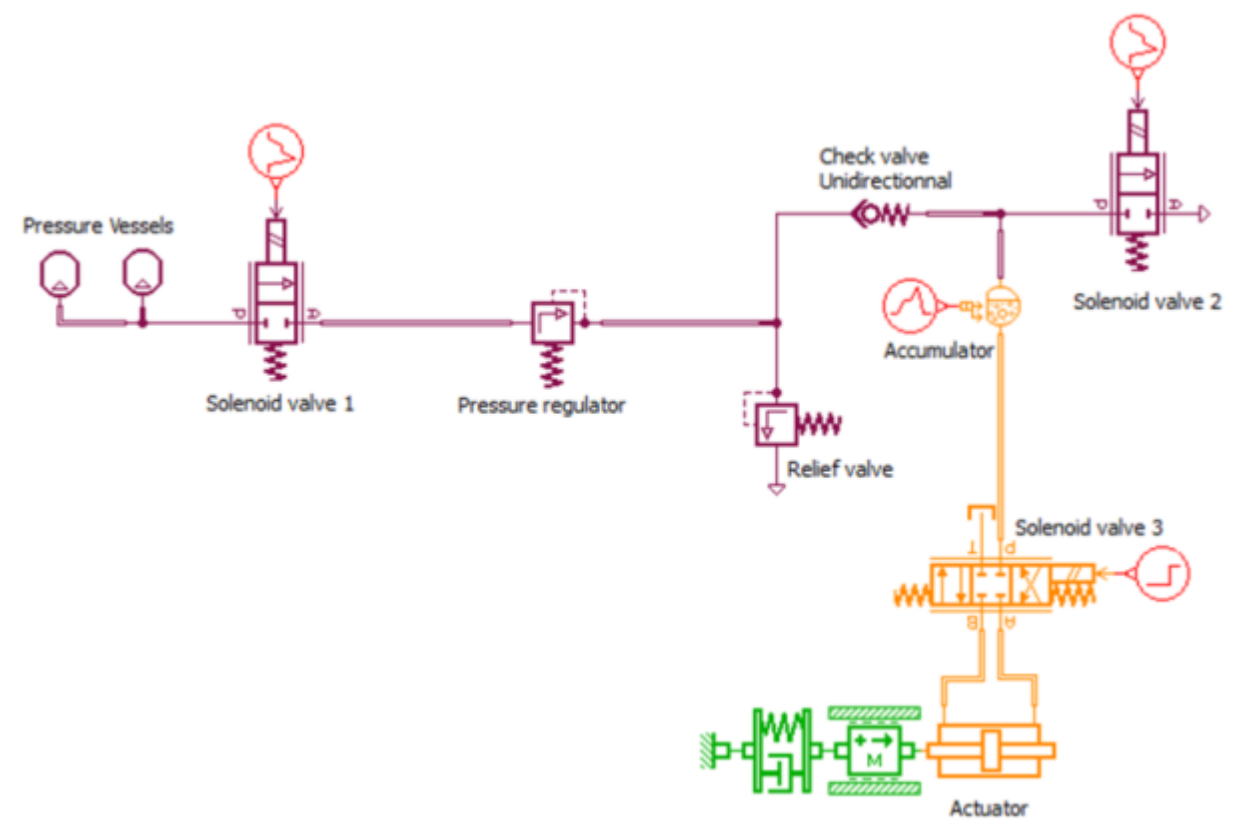

Figure 5 - Simplified Model of PFS/FEHA (AMESim environment).

The Figure 6 shows the PFS unit-step response using helium and nitrogen gas obtained from AMEsim simulation. For that, the gas parameters are presented in the Table 1.

\begin{tabular}{l|l|l}
\multicolumn{3}{c}{ Table 1 - Properties of Nitrogen and Helium } \\
\hline & Nitrogen & Helium \\
\hline Symbol & $\mathrm{N}$ & $\mathrm{He}$ \\
Atomic number & 7 & 2 \\
Atomic mass & 14.0067 & 4.0026 \\
Boiling point & $77 \mathrm{~K}$ & $4 \mathrm{~K}$ \\
Triple point & $63.153 \mathrm{~K}$ & - \\
Triple point & $12.53 \mathrm{kPa}$ & - \\
Critical point & $126.19 \mathrm{~K}$ & $5.19 \mathrm{~K}$ \\
Triple point & $3.398 \mathrm{MPa}$ & $0.227 \mathrm{MPa}$ \\
Heat of Vaporization & $5.56 \mathrm{~kJ} / \mathrm{mol}$ & $0.0829 \mathrm{~kJ} / \mathrm{mol}$ \\
\hline
\end{tabular}

As depicted in Figure 6, helium provides a shorter rise time (observed in the actuator piston displacement) than nitrogen. Indeed, helium pressure increases and decreases much faster than nitrogen pressure. The Figure 7 shows the step response obtained from the PFS and the MAQDRAU operation, using nitrogen gas. 


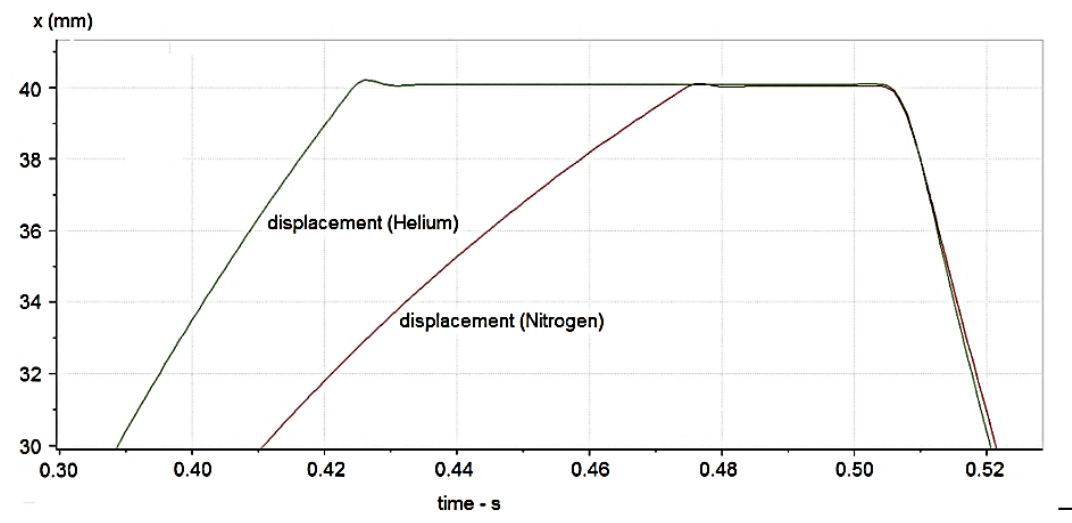

Figure 6: AMEsim simulation: input signal and response for gas helium and nitrogen.

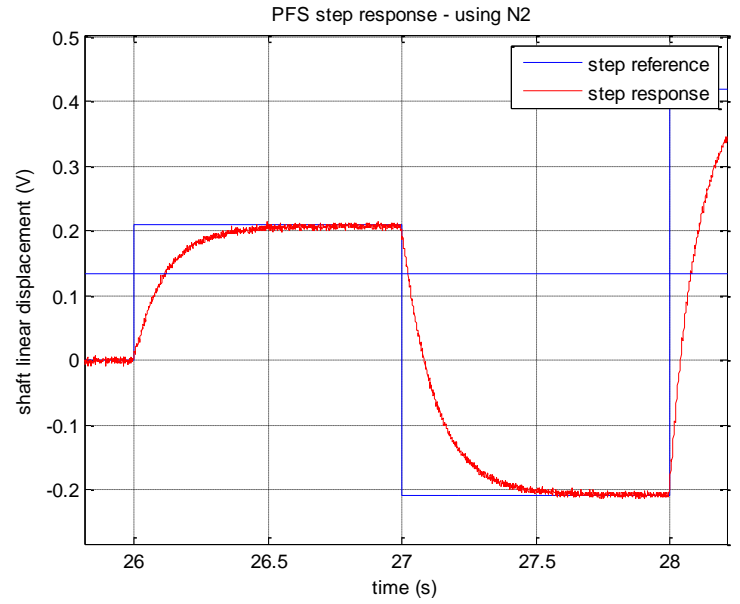

Figure 7 - PFS and hydraulic actuator step response using nitrogen.

A testbed can perform time and frequency domain test with and without a known load, consisting of a massspring-dumper in which its parameters are listed in the Table 2.

Table 2 - hydraulic actuator test bench parameters

\begin{tabular}{|c|c|c|c|}
\hline Masses [kg] & Springs $[\mathrm{kg} / \mathrm{mm}]$ & Pressure [bar] & Sensors \\
\hline 10.10 & 0.43 & 128 & $\begin{array}{l}\text { Displacement } \\
\text { sensor }\end{array}$ \\
\hline 20.55 & 1.10 & 200 & $\begin{array}{l}\text { Oil temperature } \\
\text { sensor }\end{array}$ \\
\hline 30.30 & 2.48 & - & $\begin{array}{l}\text { Oil temperature } \\
\text { sensor }\end{array}$ \\
\hline 40.50 & 4.25 & - & Load cell \\
\hline - & 6.03 & - & Flow meter \\
\hline
\end{tabular}

Results from frequency test were performed to the FEHA and plotted in the Figure 8 as well as the frequency response function to the lower order equivalent system (LOES) from system identification. The LOES transfer function to the closed loop operation MAQDRAU actuator is

$$
T(s)=\frac{18.8}{s+18.8}
$$


in which the bandwidth is $B_{w}=3 \mathrm{~Hz}$, pointed out in the Bode diagram shown in Figure 8 for $-3 \mathrm{~dB}$ gain and $45^{\circ}$ phase.
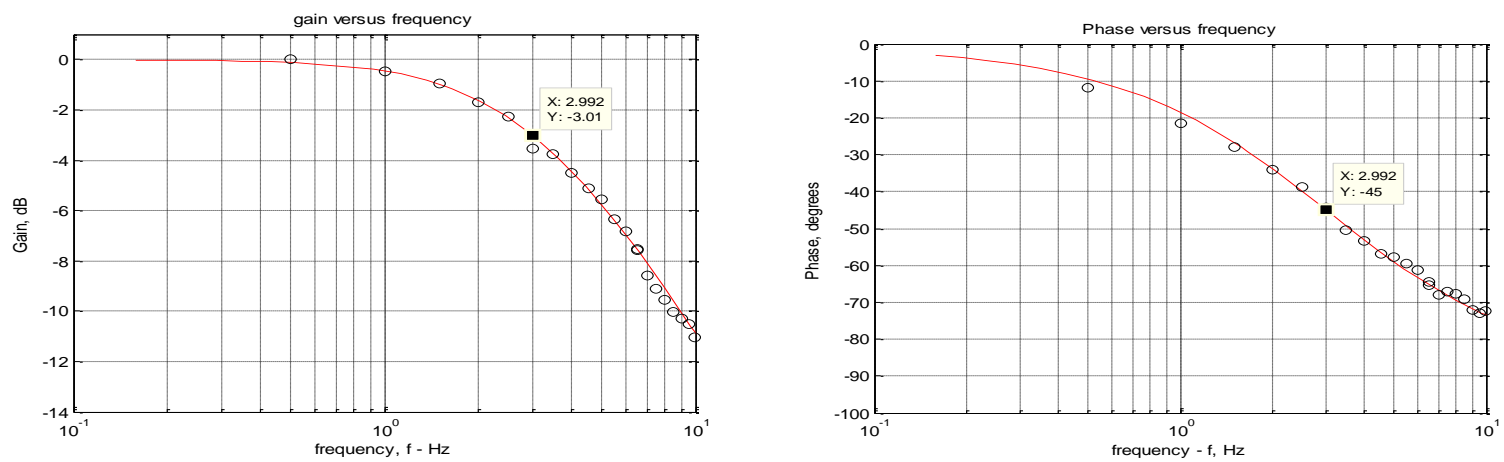

Figure 8 - MAQDRAU actuator Bode diagram (left) gain and (right) phase circles $=$ from experimental data; solid $=$ from system identification .

\section{CONCLUSION}

This work presents a PFS and a hydraulic actuator that can be applied to Brazilian vehicles with TVA systems for attitude control, encouraged by the restrictive international acquisition of such equipment for rocket and launcher application. Engineering models were mounted at IAE's laboratory and are under testing for performance verification. Actually, some mechanical optimization is in course focusing the bandwidth improvement as well as mass and volume minimization. The choice of helium to the PFS leads on technological components and very expensive devices as well as the development of fast servovalves to space application.

Hydraulic actuators have nonlinear behavior according to the amplitude of excitation, and for small displacements we can obtain first and second order linear models. The main nonlinearities are presented as flow saturation, hydraulic flow equation and voltage-to-electromagnetic force conversion in the servo-valve.

The bandwidth is a very important parameter for rocket and launcher control design, just because it relates directly the vehicle control capability against external disturbances (wind and inter stage separation efforts, aerodynamics and mechanical inaccuracy). The actual engineering model to the PFS and hydraulic actuator MAQDRAU has presented good performance $(B w>3.0 \mathrm{~Hz}, 140 \mathrm{~mm} / \mathrm{s}$ rod linear velocity, $20 \mathrm{kN}$ static force) and the improvements mentioned in this work, together with other kind of hydraulic control (digital servovalve), certainly will produce fast hydraulic actuators.

\section{REFERENCES}

[1] Ettl, et al, Development of the VS-50 as an intermediate step towards VLM-1, European Space Agency, 22nd ESA Symposium on European Rocket and Balloon Programmers and Related Research, ESA SP-730, 2015.

[2] A. L. Greensite, Control Theory: Analysis and Design of Space Vehicle Flight Control Systems, Spartan Books, 1970.

[3] Merrit, H., Hydraulic Control Systems,John Wiley \& Sons, Inc., New York, 1967.

[4] M. Jelali and A. Kroll, Hydraulic servo-systems. Springer, 2003.

[5] Karnopp, D., Margolis, D., \& Rosenberg, R., System Dynamics: A Unified Approach, 1990.

[6] Barbosa, E. C. M. B., Wekerle, T., Batagini, C. M., Brazilian Thrust Vector Control System Development: Status and Trends, Propulsion and Energy Forum, July 25-27, Salt Lake City, UT, http://arc.aiaa.org | DOI: 10.2514/6.20164909. 52nd AIAA/SAE/ASEE, 2016.

[7] Barbosa, E. C. M. B., Wekerle, T., Batagini, C. M., Closed-loop actuator identification for Brazilian Thrust Vector Control development. In: International Federation of Automatic Control, 2016, Shrebrok. 20th IFAC Symposium on Automatic Control in Aerospace - ACA 2016. Toronto: IFAC, 2016. v. 12. p. 233-243.

[8] Barbosa, E. G., Modeling via Bong Graphs of a flexible structure controlled by a hydraulic actuation, Technological Institute of Aeronautics - ITA, Master Dissertation, 2001.

[9] G. P. Sutton and O. Biblarz. Rocket Propulsion Elements 8 th ed. John Wiley \& Sons, Inc., Hoboken, New Jersey, 2010. ISBN 978-0-470-08024-5 